\title{
RESEARCH
}

\section{Breast size and risk of type 2 diabetes mellitus}

\author{
Joel G. Ray MD MSc, Anshu P. Mohllajee MPH, Rob M. van Dam PhD, Karin B. Michels ScD PhD
}

$\infty$

See related article page 3I3

\section{ABSTRACT}

Background: Elevated waist circumference and body mass index (BMI), both traditional measures of obesity, are accepted risk factors for type 2 diabetes mellitus. Girls who are obese experience earlier onset of puberty and possibly greater breast development. We sought to evaluate whether a woman's breast size in late adolescence is associated with an increased risk of type 2 diabetes mellitus in adulthood.

Methods: In conjunction with the ongoing Nurses' Health Study II, which began to study risk factors for breast cancer among women in 1989 , we conducted a prospective cohort study involving 92106 of the participants. We assessed the risk of type 2 diabetes mellitus in relation to self-reported bra cup sizes, categorized as $\leq A, B, C$ and $\geq D$ cups, among participants at age 20 .

Results: The mean age of participants at baseline was 38.1 years. A total of 1844 new cases of type 2 diabetes mellitus arose at a mean age of 44.9 years during 886443 personyears of follow-up. Relative to bra cup size $\leq \mathrm{A}$, the respective age-adjusted hazard ratios (and $95 \%$ confidence intervals [Cls]) were 2.30 (1.99-2.66) for B cup, 4.32 (3.71-5.04) for C cup and 4.99 (4.12-6.05) for $\geq D$ cup. Upon further adjustments for age at menarche, parity, physical activity, smoking status, diet, multivitamin use, family history of diabetes mellitus, BMI at age 18 and current $\mathrm{BMI}$, the corresponding hazard ratios (and 95\% Cls) were $1.37(1.18-1.59)$ for $B$ cup, 1.80 (1.53-2.11) for $C$ cup and 1.64 (1.34-2.01) for $\geq$ D cup. The addition of waist circumference to this model minimally changed the hazard ratios (and 95\% Cls): $1.32(1.14-1.53)$ for B cup, 1.71 (1.46-2.01) for $C$ cup and 1.58 (1.29-1.94) for $\geq D$ cup.

Interpretation: A large bra cup size at age $\mathbf{2 0}$ may be a predictor of type 2 diabetes mellitus in middle-aged women. Whether this relation is independent of traditional indicators of obesity remains to be determined.

Une version française de ce résumé est disponible à l'adresse www.cmaj.ca/cgi/content/full/178/3/289/DCI

CMAJ 2008;178(3):289-95

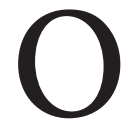

besity is an established risk factor for type 2 diabetes mellitus. ${ }^{1,2}$ Affected individuals show signs of insulin resistance and hyperinsulinemia, a process that may begin in childhood. ${ }^{3,4}$ Pre-adolescent obesity is also an important predictor of age of onset of breast development in young women, and of breast size after puberty. ${ }^{5,6}$ Premature onset of puberty is preceded by childhood insulin resistance, hyperinsulinemia and hyperandrogenemia, ${ }^{7}$ which may persist after puberty ${ }^{8}$ and continue into early adulthood. 9

Although an elevated body mass index (BMI) ${ }^{10,11}$ and central adiposity ${ }^{12}$ are established risk factors for insulin resistance and the onset of type 2 diabetes mellitus, little is known about the contribution of extra-abdominal adipose tissue, including breast tissue, about $60 \%$ of which is fatty tissue, to this process. ${ }^{13,14}$ We hypothesized that a woman's breast size in late adolescence reflects her predisposition to insulin resistance and type 2 diabetes mellitus that is both additive to, and independent of, BMI. We explored this hypothesis in conjunction with the Nurses' Health Study II by relating bra cup size, a proxy for breast size, to the onset of type 2 diabetes mellitus.

\section{Methods}

\section{Participants}

The Nurses' Health Study II is a prospective cohort study, which was initiated in 1989 and is ongoing. The study involves II6 609 women, more than $90 \%$ of whom are white, from I4 US states. ${ }^{15}$ At the time of enrolment, participants were between the ages of 25 and 42, and they completed a detailed baseline questionnaire about their health, lifestyles and anthrometric characteristics. They continue to complete follow-up questionnaires on a biennial basis. We included all women who had concomitant information about bra cup size at age 20 and BMI at age 18 , for a total of 92 Io6 participants. We excluded women who had already received a diagnosis of diabetes mellitus or who had a history of gestational diabetes. Our study was approved by the Human Research Committees at the Harvard School of Public Health and the Brigham and Women's Hospital in Boston, Massachusetts.

From the Departments of Medicine, Obstetrics and Gynecology, and Health Policy Management and Evaluation, and the Li Ka Shing Knowledge Institute, St. Michael's Hospital, University of Toronto (Ray), Toronto, Ont.; the Department of Epidemiology, Harvard School of Public Health (Mohllajee), Boston, Mass.; the Department of Nutrition, Harvard School of Public Health, and the Department of Nutrition and Health, Institute for Health Sciences, Vrije Universiteit (van Dam), Amsterdam, the Netherlands; the Channing Laboratory, Department of Medicine, Brigham and Women's Hospital, Harvard Medical School, and the Department of Epidemiology, Harvard School of Public Health (Michels), Boston, Mass. 


\section{Assessment of bra cup size}

Bra cup size is traditionally determined by measuring the horizontal chest circumference just under the breasts, adding 5 inches $(12.7 \mathrm{~cm})$ and subtracting the total from the horizontal chest circumference at the fullest part of the breasts. A net difference of $\mathrm{I}$ inch is equivalent to an A cup, 2 inches a B cup, 3 inches a C cup and 4 inches a D cup. ${ }^{16}$ On the 1993 Nurses' Health Study II questionnaire, women were asked to recall their bra cup size at age 20 and indicate whether it was an A cup or smaller, B cup, C cup, or a D cup or larger. Those who did not wear a bra were asked to estimate their bra cup size. ${ }^{17}$ Participants were not asked to formally measure their chest circumferences.

\section{Assessment of type 2 diabetes mellitus}

We assessed the incident onset of type 2 diabetes between 1993 (when the Nurses' Health Study II first recorded bra cup size) and 2003. We asked each woman who reported a diagnosis of diabetes on a biennial questionnaire during our study period to complete a supplemental form containing questions about symptoms, diagnostic tests and receipt of hypoglycemic therapy. We confirmed the diagnosis based on I or more of the following criteria: presence of I or more classic symptoms of diabetes (polydipsia, polyuria, weight loss or hunger) and either a fasting plasma glucose level of $7.8 \mathrm{mmol} / \mathrm{L}$ or more or a random plasma glucose level of II.I mmol/L or more; at least 2 instances of hyperglycemia (fasting plasma glucose level of $\geq 7.8 \mathrm{mmol} / \mathrm{L}$, random plasma glucose level of $\geq$ II.I mmol/L or oral glucose tolerance test result of $\geq$ II.I mmol/L after 2 hours) on different occasions in the absence of symptoms; and treatment with insulin or an oral hypoglycemic medication. ${ }^{18}$ In 1997, in keeping with the revised American Diabetes Association criteria, the cutoff for fasting plasma glucose levels was lowered to $7.0 \mathrm{mmol} / \mathrm{L} .{ }^{19}$ In a prior validation study of the Nurses' Health Study, an endocrinologist confirmed that the same supplementary questionnaire accurately ascertained $98 \%$ of cases of type 2 diabetes among study participants. ${ }^{20}$

\section{Assessment of other variables}

At the time of enrolment in the Nurses' Health Study II, participants reported information on height and weight at age I8 and current weight. Information on current weight was updated every 2 years thereafter. Self-reported height and weight at age 18 were previously validated ${ }^{21,22}$ and were found to be reported with high accuracy (Pearson correlation coefficients 0.87 for height and 0.94 for weight). ${ }^{21}$ We obtained data on waist circumference, measured at the level of the umbilicus, from the I993 survey; the Pearson correlation coefficient between self-reported and technician-measured waist circumference was $0.89 .^{22}$

Study participants completed a food frequency questionnaire every 4 years; its reproducibility and validity have been confirmed..$^{23}$ We calculated a dietary score for each woman based on her intake of trans fats and cereal fibre, the ratio of polyunsaturated fat to saturated fat and the glycemic load. The scores ranged from $\mathrm{I}$ to 5 , with a higher score predicting a lower risk of diabetes. ${ }^{24}$ The scores for the individual dietary factors were summed, and the mean composite score is pre- sented herein. Participants reported multivitamin use as "yes" or "no." On the I99I and I999 questionnaires, the Nurses' Health Study II participants reported data on physical activity, which we assessed by calculating the total number of hours per week that participants engaged in moderate to vigorous activities from a specified list. The reproducibility and validity of this method have been confirmed. ${ }^{25}$ Participants reported past and current smoking history on each biennial questionnaire.

Parity was based on the number of pregnancies that lasted longer than 6 months. Participants reported information about pregnancy at the time of enrolment and on each subsequent biennial questionnaire. They reported their age at menarche on the I 989 questionnaire. We determined the cumulative number of months of lactation using the total number of months from each delivery to cessation of breastfeeding, as reported on the I993, I997 and 2003 questionnaires. Finally, participants reported family history of diabetes mellitus on the I989 and I997 questionnaires.

\section{Assessment of adiposity in childhood}

A 9-level figure drawing in the 1989 survey allowed participants to report their body fat scores at ages 5 and ro. Scores for each age ranged from I to 5 or higher, with a score of I indicating little or no body fat, and higher scores indicating increasing leves of body fat. ${ }^{26}$

\section{Statistical analysis}

We excluded participants who did not report bra cup size or BMI at age I8. We began our analysis of participants' data when they returned the I993 questionnaire reporting bra cup size and ended the analysis for each participant upon diagnosis of type 2 diabetes, death or the end of the study period in 2003, whichever occurred first.

We used a Cox proportional hazards model to generate an age-adjusted hazard ratio and 95\% confidence interval (CI) to determine the risk of type 2 diabetes in relation to BMI at age I8, using the lowest BMI quintile as the reference group. We then expanded our analysis to include age at menarche, parity, cumulative number of months of lactation, hours per week of physical activity, smoking status, mean dietary score, multivitamin use, family history of diabetes mellitus in I989 and bra cup size at age 20.

We developed 5 models (models A to E) to determine the relation between bra cup size and risk of diabetes. We used a Cox proportional hazards model to generate an age-adjusted hazard ratio and $95 \% \mathrm{CI}$, comparing women who wore B cups or larger with women in the reference group ( $\leq \mathrm{A}$ cup). In model A, we adjusted for current age, age at menarche, parity (o, I, 2, $\geq 3$ ), cumulative number of months of lactation, hours per week of physical activity ( $<$ I, I to $<2,2$ to $<4,4$ to $\leq 7$ and $>7$ ), smoking status (never, past, I-I4 cigarettes/d, I5-24 cigarettes/d, $\geq 25$ cigarettes/d), mean dietary score ( $\mathrm{I}-5$ ), multivitamin use (yes or no) and the presence of a family history of diabetes in I989. Model B, the main analysis, expanded upon model A and included adjustment for BMI at age I8. In model $B$, we evaluated the relation between bra cup size and type 2 diabetes among each BMI quintile at age I8 years. We evaluated whether model B (the stratified model) better determined the 
relation between BMI and bra cup size than model A (the nonstratified model) using a likelihood ratio test. Because of the broad range of BMI values within each quintile, it was necessary to adjust for BMI as a continuous variable among the groups to avoid within-group confounding. We adjusted model C to include participants' most recent BMI. Model D included an adjustment for change in weight (in kilograms) between age I 8 and age at the time of completing the most recent biennial follow-up questionnaire; however, it did not include an adjustment for most recent BMI. Model E included both an adjustment for most recent BMI and waist circumference in 1993 in addition to the adjusted variables in model B.

\section{Results}

Of the original cohort of II 6609 women enrolled in the Nurses' Health Study II, we excluded 2032 women for whom there were a number of missing variables, and we excluded a further 22 08I women because of a lack of information on bra cup size. We excluded an additional 390 women because of a history of gestational diabetes or because they had already received a diagnosis of diabetes. We included a total of 92 I06 women in our analysis. The mean age at baseline (1993) was 38.I years. BMI at age 18 years and in 1993 , and waist circumference in 1993, increased in a linear fashion with larger bra cup size (Table I). The mean score for body fat in childhood also increased with bra cup size at age 20 (Table I). Conversely, women with a larger bra cup size were younger at menarche than women with the smallest cup size (reference group). Women in the largest bra cup size category were about $4.1 \%$ more likely to be nulliparous than women in the smallest category (Table I). The proportion of participants with a family history of diabetes was higher among women with larger bra cup sizes than among those with the smallest cup size. Women with larger bra cup sizes were more likely than those in the smallest category to have smoked.

Table 1: Age-standardized characteristics of 92106 participants of Nurses' Health Study II, at baseline (1993)

\begin{tabular}{|c|c|c|c|c|}
\hline Characteristic & \multicolumn{4}{|c|}{ Bra cup size; no. (\%) of participants* } \\
\hline Age, yr, mean & 38.3 & 38.1 & 37.8 & 38.4 \\
\hline \multicolumn{5}{|l|}{ Body mass index, $\mathrm{kg} / \mathrm{m}^{2}$, mean } \\
\hline At age 18 & 19.9 & 21.3 & 22.6 & 23.8 \\
\hline Waist circumference in $1993, \mathrm{~cm} \dagger$, mean & 74.8 & 78.7 & 81.3 & 83.5 \\
\hline \multicolumn{5}{|l|}{ Body fat score $\neq$, mean } \\
\hline At age 5 & 2.2 & 2.5 & 2.6 & 2.7 \\
\hline At age 10 & 2.4 & 2.8 & 3.0 & 3.1 \\
\hline Age at menarche, yr, mean & 12.6 & 12.4 & 12.1 & 12.2 \\
\hline 2 & 10147 (37.5) & $16693(37.8)$ & $6061(37.0)$ & $1537(34.1)$ \\
\hline$\geq 3$ & 6359 (23.5) & $10334(23.4)$ & $3735(22.8)$ & 987 (21.9) \\
\hline Cumulative no. of months of lactation, mean & 16.6 & 15.7 & 15.6 & 16.3 \\
\hline Dietary score§, mean & 2.7 & 2.7 & 2.7 & 2.7 \\
\hline Multivitamin use & $12311(45.5)$ & 19387 (43.9) & $7060(43.1)$ & $1947(43.2)$ \\
\hline $\begin{array}{l}\text { Moderate to vigorous exercise, hours per week, } \\
\text { mean }\end{array}$ & 3.7 & 3.8 & 3.8 & 3.6 \\
\hline \multicolumn{5}{|l|}{ Smoking history } \\
\hline Never & $18508(68.4)$ & $28793(65.2)$ & $10172(62.1)$ & $2767(61.4)$ \\
\hline
\end{tabular}

*Unless stated otherwise.

tInformation available for 49003 (53.2\%) of all participants.

¥Scores ranged from 1 to 5 or higher, with a score of 1 indicating little or no body fat, and higher scores indicating increasing levels of body fat.

§Scores ranged from 1 to 5 , with a score of 1 indicating a higher risk of type 2 diabetes, and higher scores indicating a lower risk. 
During 886443 person-years of follow-up, I844 incident cases of type 2 diabetes were reported. Relative to the group with the lowest BMI at age $\mathrm{I} 8$ years $(\leq \mathrm{I} 8.8)$, the age-adjusted hazard ratios (and $95 \%$ CIs) for type 2 diabetes mellitus were 0.94 (0.76-I.I6) for the I8.9-20.I BMI group, I.33 (I.09-I.62) for the 20.2-2I.2 BMI group, 2.I4 (I.79-2.56) for the 2I.3-23.0 BMI group and $5.05(4.29-5.95)$ for the $\geq 23 . I$ BMI group. After adjustment for age, age at menarche, parity, cumulative number of months of lactation, hours per week of physical activity, number of cigarettes smoked per day, mean dietary score, multivitamin use, family history of diabetes mellitus in 1989 and bra cup size at age 20 , the covariableadjusted hazard ratios (and 95\% CIs) were 0.88 (o.7I-I.09) for the I8.9-20.I BMI group, I.I5 (0.94-I.40) for the 20.2-21.2 BMI group, I.64 (I.36-I.97) for the 2I.3-23.0 BMI group and $2.94(2.47-3.50)$ for the $\geq 23.1$ BMI group.

The onset of diabetes was 2.I years earlier among women who wore a D cup or larger (mean 43.7 years) compared with those who wore an A cup or smaller (mean 45.8 years). Relative to the smallest bra cup size, the age-adjusted hazard ratios were 2.30 for B cup, 4.32 for C cup and 4.99 for D cup or larger (Table 2). These risk estimates were slightly attenu- ated after we adjusted for the covariables in model A. Additional adjustment for BMI at age 18 (model $\mathrm{B}$ ) and current BMI (model C) attenuated the associations further, but the risk of diabetes mellitus remained significantly higher with increasing cup size (Table 2).

After adjusting for BMI at age I8 and weight change, we found that the relative risk of type 2 diabetes was I.4I ( $95 \% \mathrm{CI}$ I.2I-I.63) times higher among women who wore a B cup, I.85 (I.58-2.I8) times higher among women who wore a C cup and I.7I (I.39-2.IO) times higher among women who wore a D cup or larger, as compared with women who wore an A cup or smaller (model D, Table 2). Including the square of BMI at age $\mathrm{I} 8$ in model D did not alter these risk estimates (data not shown). When we adjusted for both waist circumference in 1993 and most recent BMI (model E), we found that the risk of type 2 diabetes changed minimally, with a hazard ratio (and 95\% CIs) of I.32 (I.I4-I.53) for B cup, I.7I (I.46-2.0I) for $\mathrm{C}$ cup and I.58 (I.29-I.94) for $\geq \mathrm{D}$ cup (Table 2).

Compared with women in the group with the lowest BMI at age 18 who wore an A cup or smaller, women who were in the 2I.3-23.0 BMI group and wore a D cup or larger had about a 3 times higher risk of type 2 diabetes (hazard ratio

Table 2: Risk of type 2 diabetes mellitus in relation to bra cup size among 92106 participants of Nurses' Health Study II

\begin{tabular}{|c|c|c|c|c|c|}
\hline Assessment & \multicolumn{4}{|c|}{ Bra cup size } & $p$ value \\
\hline No. of person-years of follow-up & 261877 & 425178 & 156572 & 42816 & - \\
\hline $\begin{array}{l}\text { No. of incident cases of type } 2 \\
\text { diabetes mellitus }\end{array}$ & 232 & 850 & 570 & 192 & - \\
\hline Age-adjusted hazard ratio $(95 \% \mathrm{Cl})$ & 1.009 & $2.30(1.99-2.66)$ & $4.32(3.71-5.04)$ & $4.99(4.12-6.05)$ & $<0.001$ \\
\hline $\begin{array}{l}\text { Model } A \text { : covariable adjusted } \\
\text { hazard ratio }(95 \% \mathrm{Cl})^{*}\end{array}$ & 1.009 & $2.14(1.85-2.47)$ & $3.80(3.26-4.43)$ & $4.12(3.40-5.00)$ & $<0.001$ \\
\hline $\begin{array}{l}\text { Model B: covariable adjusted } \\
\text { hazard ratio }(95 \% \mathrm{Cl}) \text {, also } \\
\text { adjusted for } \mathrm{BMI} \text { at age } 18 \dagger\end{array}$ & 1.009 & $1.75(1.51-2.03)$ & $2.60(2.21-3.05)$ & $2.37(1.93-2.90)$ & $<0.001$ \\
\hline $\begin{array}{l}\text { Model } D \text { : covariable adjusted } \\
\text { hazard ratio }(95 \% \mathrm{Cl}) \text {, also } \\
\text { adjusted for } \mathrm{BMI} \text { at age } 18+\text { and } \\
\text { weight change } \neq\end{array}$ & 1.009 & $1.41(1.21-1.63)$ & $1.85(1.58-2.18)$ & & $<0.001$ \\
\hline $\begin{array}{l}\text { Model E: covariable adjusted } \\
\text { hazard ratio }(95 \% \mathrm{CI}) \text {, also } \\
\text { adjusted for } \mathrm{BMI} \text { at age } 18 \text {, } \\
\text { current BMl† and waist } \\
\text { circumference in } 1993 \S\end{array}$ & $1.00 \eta$ & $1.32(1.14-1.53)$ & $1.71(1.46-2.01)$ & $1.58(1.29-1.94)$ & $<0.001$ \\
\hline
\end{tabular}

Note: $\mathrm{Cl}=$ confidence interval, $\mathrm{BMI}=$ body mass index.

*Adjusted for age, age at menarche, parity, cumulative no. of months of lactation, hours per week of physical activity, no. of cigarettes smoked per day, mean dietary score, multivitamin use and family history of diabetes mellitus in 1989.

†Measured as a continuous variable.

¥Net weight change, in kilograms, between age 18 years and the last available weight measure before the end of the period of observation.

§Measured as a continuous variable.

IReference group. 
3.I4, 95\% CI 2.II-4.68). Women who were in the $\geq 23 . \mathrm{IBMI}$ group and wore a D cup or larger had a hazard ratio of 2.46 (95\% CI I.75-3.46) (Figure I). We found that the interaction between BMI quintile at age I8 and bra cup size was not significant $(p=0.90)$.

\section{Interpretation}

In our prospective cohort study involving young and middleaged women, we found that a larger bra cup size at age 20 predicted the onset of type 2 diabetes. Bra cup size, a simple, easily ascertained measure, explained the association beyond the well-established measure of BMI. The association held true within all BMI groups and also appeared to follow a dose-response relation. The association also persisted after we adjusted for other risk factors for type 2 diabetes, such as family history of diabetes mellitus, diet and exercise. Furthermore, by developing 5 separate models to determine the relation between bra cup size and risk of diabetes, each model adjusting for different covariables, we found that the relative risk of diabetes was greater among women with larger bra cup sizes than among those in the reference group ( $\leq$ A cup size) in all models (Table 2). This finding illustrates that, whatever the approach to adjustment, there may be additional benefit to include breast size in the assessment of risk factors for type 2 diabetes.

Bra cup size, when properly determined, provides a reasonable cross-sectional estimate of overall breast volume. ${ }^{16}$ Kusano and colleagues ${ }^{17}$ have successfully studied the relation between breast size and breast cancer risk using cup size divisions similar to ours. Although better methods, including magnetic resonance imaging, exist for measuring

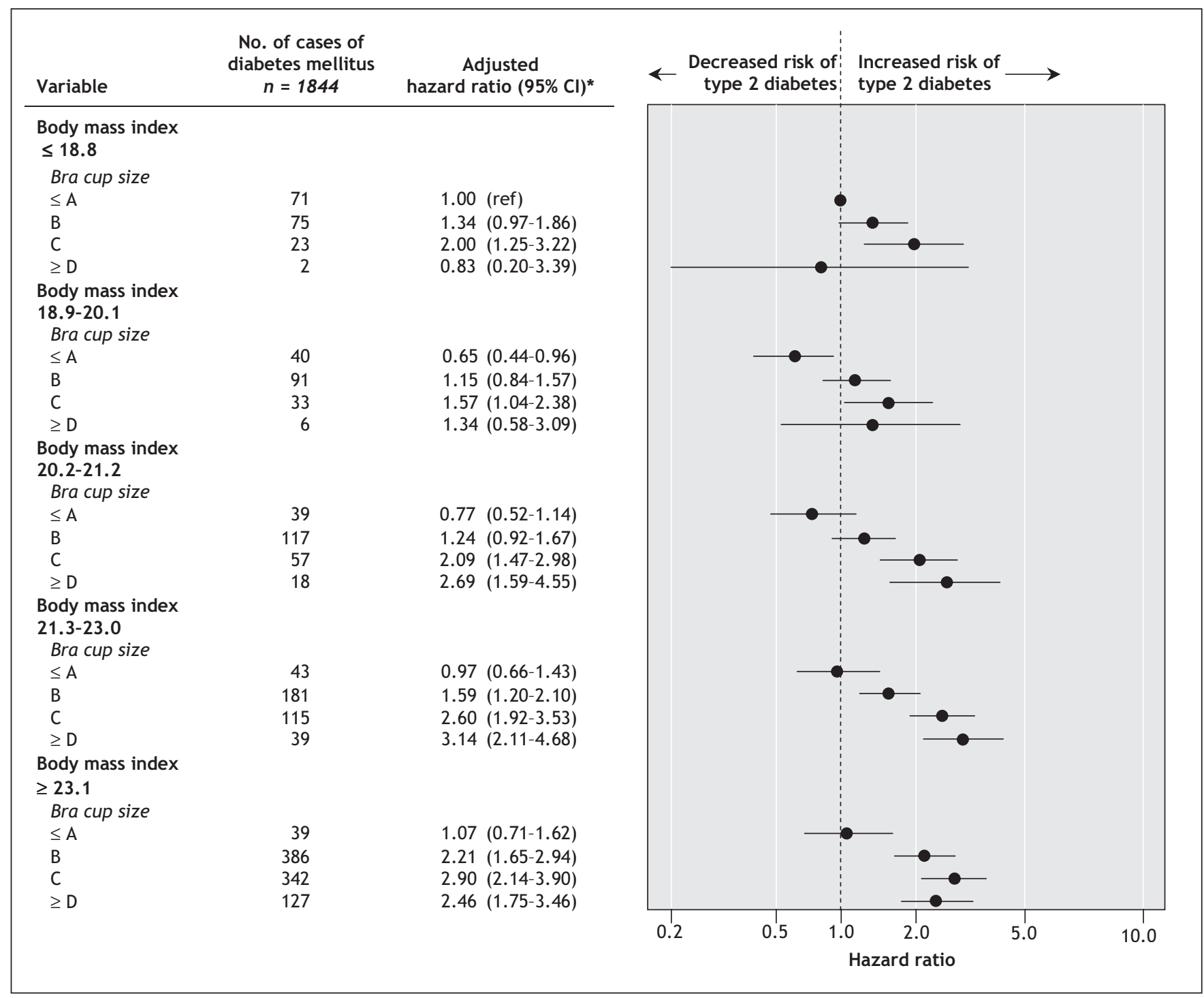

Figure 1: Forest plot showing risk of type 2 diabetes mellitus in relation to body mass index and bra cup size among 92106 women involved in the Nurses' Health Study II. *Model B: adjusted for age, age at menarche, parity, cumulative no. of months of lactation, physical activity, smoking status, mean dietary score, multivitamin use, family history of diabetes and body mass index at age 18 . $\mathrm{Cl}=$ confidence interval, ref = reference group. 
breast fat volume, they are expensive and time-consuming, and breast fat volume varies by about $15 \%$ across a woman's menstrual cycle. ${ }^{27}$

If our findings prove to be true, they raise a number of new questions about the pathogenesis of type 2 diabetes. Although it is not known whether adipose tissue in the breast contributes to the pathogenesis of insulin resistance, posterior chest adiposity - marked by a high ratio of subscapular to triceps skinfold thickness - is positively correlated with insulin resistance and type 2 diabetes. ${ }^{28}$ The storage of steroid hormones within breast tissue, and the behaviour of breast tissue as a paracrine and autocrine organ, including expression of insulin-like growth factor-I by mammary adipocytes, has been widely discussed in relation to breast cancer, ${ }^{29,30}$ but not in relation to diabetes. Adiponectin and leptin - hormones produced by adipose tissue that are responsible for regulation of glucose and fatty acid metabolism and appetite - have recently been found to be secreted in breast milk. ${ }^{31,32}$ Whether these hormones are expressed in breast tissue of nonlactating women remains unknown. Thus, while abdominal visceral obesity is known to contribute to the development of insulin resistance, ${ }^{3,12}$ the additional action of hormonally active breast adipose tissue within this process requires elucidation.

We hypothesized that prepubertal obesity may accelerate and exaggerate the normal state of insulin resistance seen in puberty. ${ }^{33}$ Although we did not directly test this hypothesis, the observed positive association between self-rated body fat in childhood (especially at age ro) and bra cup size, and the inverse association between age at menarche and bra cup size, is consistent with this concept. ${ }^{5,6}$ Breast size after puberty may also be a marker of postpubescent excessive insulin secretion and hyperandrogenemia. ${ }^{8,9}$ It is thus conceivable that breast size in early adulthood (e.g., at age 20) is a marker of childhood adiposity and peripubertal insulin resistance, which may continue into adulthood.

A cross-sectional study of the relation between breast volume determined by magnetic resonance imaging, markers of insulin resistance, and the metabolic syndrome among preand postpubertal women could clarify the mechanisms by which breast adiposity may predispose a young woman to type 2 diabetes. ${ }^{34}$ In addition, an accurate evaluation of chest adiposity in men and women may help decipher the degree to which breast fat tissue ${ }^{28}$ versus extra-abdominal fat contributes to the overall risk of insulin resistance and type 2 diabetes. Consideration of ethnic background and socioeconomic status in each of these studies is also recommended.

Our study had several strengths: a large sample, near complete prospective long-term follow-up and the use of a standard definition for type 2 diabetes. Other variables potentially associated with the development of diabetes, such as selfreported height, weight and waist circumference, have been previously validated. ${ }^{21,22}$ Our study has a number of limitations. One limitation was that we relied on the women's recall of their bra cup size at age 20, which was a key variable in the study. If underweight and obese women over- and underestimated their bra cup size at age 20 , respectively, then the true relation between breast size and risk of diabetes may have been underestimated. Direct measurement of breast size and adiposity by physical examination or magnetic resonance imaging would have been useful herein. Another potential limitation was that we did not ask about breast augmentation, in part because cosmetic breast surgery was uncommon at the time that the study was initiated. Another limitation relates to the individuals enrolled in the study. The majority of our study participants were white; therefore, we are unsure whether our results would hold true for women of other ethnic backgrounds. ${ }^{28} \mathrm{~A}$ fair number of participants did not report bra cup size at age 20. Only about I8\% of the Nurses' Health Study II participants included in this study wore a C cup bra at age 20 , and only $5 \%$ wore a D cup or larger. Moreover, the risk of type 2 diabetes in relation to larger bra cup size was only modest. On the other hand, we found BMI at age 18 to be a strong independent predictor of diabetes, a finding that is consistent with results from other studies. ${ }^{1-3,9}$ Hence, BMI appears to be a stronger predictor of risk of type 2 diabetes than bra cup size and should remain an established measure in clinical practice. Recent Canadian guidelines also recommend measuring the waist circumference of adults when assessing obesity-related health risks. ${ }^{35}$

In summary, we documented a statistically significant association between bra cup size and the development of type 2 diabetes. We believe that our findings should be reproduced in other settings, and in studies involving women of different ethnic backgrounds. Finally, the mechanisms underlying the potential risks and health consequences of obesity in the upper and lower torso require additional research.

This article has been peer reviewed.

Competing interests: None declared.

Contributors: All of the authors participated in the design, analysis and writing of the paper, and reviewed and approved the final version.

Acknowledgements: We thank Dr. Meir Stampfer for helpful suggestions on the analyses.

Joel Ray is supported by a Canadian Institutes of Health Research New Investigator Award. This analysis was completed with financial support from the Departments of Medicine and of Obstetrics and Gynecology, and the Research Division at St. Michael's Hospital. The Nurses' Health Study II is supported by Public Health Service research grant $\mathrm{CA}_{50} \mathrm{O}_{3} 5$ from the National Cancer Institute, National Institutes of Health, Department of Health and Human Services.

The sponsors had no involvement in or control over the design and conduct of the study; the collection, analysis and interpretation of the data; the preparation of the data; or the preparation, review and approval of the manuscript.

\section{REFERENCES}

I. O'Sullivan JB. Body weight and subsequent diabetes mellitus. JAMA I982;248: 949-52.

2. Colditz GA, Willett WC, Stampfer MJ, et al. Weight as a risk factor for clinical diabetes in women. Am J Epidemiol 1990;132:50I-I3

3. Sinha R, Fisch G, Teague B, et al. Prevalence of impaired glucose tolerance among children and adolescents with marked obesity. N Engl J Med 2002;346:802-Io.

4. Galli-Tsinopoulou A, Karamouzis M, Nousia-Arvanitakis S. Insulin resistance and hyperinsulinemia in prepubertal obese children. J Pediatr Endocrinol Metab 2003;16:555-60.

5. Biro FM, Lucky AW, Simbartl LA, et al. Pubertal maturation in girls and the relation to anthropometric changes: pathways through puberty. J Pediatr 2003;142:643-6.

6. Kaplowitz PB, Slora EJ, Wasserman RC, et al. Earlier onset of puberty in girls: relation to increased body mass index and race. Pediatrics 200I;108:347-53.

7. Ibanez L, Potau N, Zampolli M, et al. Hyperinsulinemia and decreased insulin-like 
growth factor-binding protein-I are common features in prepubertal and puberta girls with a history of premature pubarche. J Clin Endocrinol Metab I997;82:2283-8.

8. Johnson MS, Figueroa-Colon R, Huang TT, et al. Longitudinal changes in body fat in African American and Caucasian children: influence of fasting insulin and insulin sensitivity. JClin Endocrinol Metab 2001;86:3182-7.

9. Folsom AR, Jacobs DR Jr, Wagenknecht LE, et al. Increase in fasting insulin and glucose over seven years with increasing weight and inactivity of young adults. The CARDIA Study. Coronary Artery Risk Development in Young Adults. Am J Epidemiol I996; I44:235-46.

ro. Whitlock EP, Williams SB, Gold R, et al. Screening and interventions for childhood overweight: a summary of evidence for the US Preventive Services Task Force. Pediatrics 2005; II6:eI25-44.

II. Deurenberg P, Yap M. The assessment of obesity: methods for measuring body fat and global prevalence of obesity. Baillieres Best Pract Res Clin Endocrinol Metab I999;I3:I-II.

I2. Despres JP. Abdominal obesity as important component of insulin-resistance syndrome. Nutrition I993;9:452-9.

I3. Cruz-Korchin N, Korchin L, Gonzalez-Keelan C, et al. Macromastia: How much of it is fat? Plast Reconstr Surg 2002;109:64-8.

I4. Boston RC, Schnall MD, Englander SA, et al. Estimation of the content of fat and parenchyma in breast tissue using MRI TI histograms and phantoms. Magn Reson Imaging 2005;23:59I-9.

15. Solomon CG, Hu FB, Dunaif A, et al. Long or highly irregular menstrual cycles as a marker for risk of type 2 diabetes mellitus. JAMA 200I;286:242I-6.

I6. Wright MC. Graphical analysis of bra size calculation procedures. Int J Cloth Sci Technol 2002;I4:4I-5

17. Kusano AS, Trichopoulos D, Terry KL, et al. A prospective study of breast size and premenopausal breast cancer incidence. Int J Cancer 2006;II8:203I-4.

I8. National Diabetes Data Group. Classification and diagnosis of diabetes mellitus and other categories of glucose intolerance. Diabetes 1979;28:1039-57.

19. Expert Committee on the Diagnosis and Classification of Diabetes Mellitus. Report of the Expert Committee on the Diagnosis and Classification of Diabetes Mellitus. Diabetes Care I997;20:1183-97.

20. Manson JE, Rimm EB, Stampfer MJ, et al. Physical activity and incidence of noninsulin-dependent diabetes mellitus in women. Lancet I99I;338:774-8.

2I. Troy LM, Hunter DJ, Manson JE, et al. The validity of recalled weight among younger women. Int J Obes Relat Metab Disord I995;19:570-2.

22. Rimm EB, Stampfer MJ, Colditz GA, et al. Validity of self-reported waist and hip circumferences in men and women. Epidemiology 1990;1:466-73.

23. Salvini S, Hunter D, Sampson L, et al. Foodbased validation of a dietary questionnaire: the effects of week-to-week variation in food consumption. Int J Epidemio I989; $8: 858-67$.

24. Hu FB, Manson JE, Stampfer MJ, et al. Diet, lifestyle, and the risk of type 2 diabetes mellitus in women. N Engl J Med 200I;345:790-7.

25. Wolf AM, Hunter DJ, Colditz GA, et al. Reproducibility and validity of a selfadministered physical activity questionnaire. Int J Epidemiol 1994;23:99I-9.

26. Baer HJ, Colditz GA, Rosner B, et al. Body fatness during childhood and adolescence and incidence of breast cancer in premenopausal women: a prospective cohort study. Breast Cancer Res 2005;7:R314-25

27. Hussain Z, Roberts N, Whitehouse GH, et al. Estimation of breast volume and its variation during the menstrual cycle using MRI and stereology. Br J Radiol I999;72:236-45

28. Haffner SM, Stern MP, Hazuda HP, et al. Upper body and centralized adiposity in Mexican Americans and non-Hispanic whites: relation to body mass index and other behavioral and demographic variables. Int J Obes 1986;10:493-502.

29. Osborne CK, Coronado EB, Kitten LJ, et al. Insulin-like growth factor-II (IGF-II): a potential autocrine/paracrine growth factor for human breast cancer acting via the IGF-I receptor. Mol Endocrinol I989;3:I70I-9.

30. Rose DP, Komninou D, Stephenson GD. Obesity, adipocytokines, and insulin re sistance in breast cancer. Obes Rev 2004;5:153-65.

3I. Bronsky J, Karpisek M, Bronska E, et al. Adiponectin, adipocyte fatty acid binding protein, and epidermal fatty acid binding protein: proteins newly identified in human breast milk. Clin Chem 2006;52:1763-70.

32. Weyermann $\mathrm{M}$, Beermann $\mathrm{C}$, Brenner $\mathrm{H}$, et al. Adiponectin and leptin in materna serum, cord blood, and breast milk. Clin Chem 2006;52:2095-ı02.

33. Potau N, Ibanez L, Rique S, et al. Pubertal changes in insulin secretion and peripheral insulin sensitivity. Horm Res I997;48:219-26.

34. Gautier JF, Mourier A, de Kerviler E, et al. Evaluation of abdominal fat distribution in noninsulin-dependent diabetes mellitus: relation to insulin resistance. JClin Endocrinol Metab I998;83:1306-II.

35. Lau DC for the Canada Clinical Practice Guidelines Expert Panel. Synopsis of the 2006 Canadian clinical practice guidelines on the management and prevention of obesity in adults and children $C M A J$ 2007;176:1103-6.

Correspondence to: Dr. Joel G. Ray, Department of Medicine, St. Michael's Hospital, 30 Bond St., Toronto ON M5B IW8; fax 4I6 864-5485; rayj@smh.toronto.on.ca
2008 BMA - AMA - CMA Internationa Conference on Doctors' Health

\section{Doctors' Health Matters - Finding The Balance}

\section{Monday 17 - Wednesday 19 November 2008}

Venue: British Medical Association,

BMA House, Tavistock Square,

London, WC1H 9JP, United Kingdom

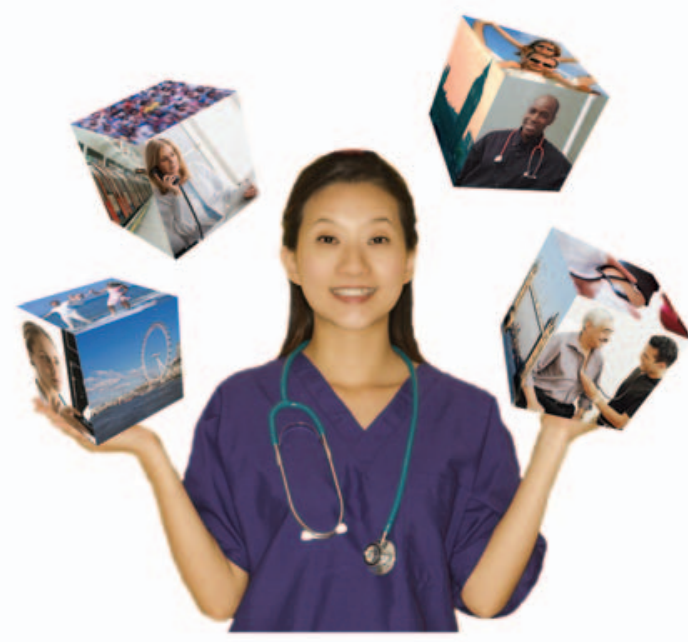

\section{ABSTRACTS INVITED}

Doctors' good health is important to all of us, both as doctors and as patients. This conference seeks to promote a healthier culture of medicine for doctors, and to reduce the stigma associated with ill health in doctors.

The conference will:

- Provide a forum for practitioners and researchers to present recent findings, innovative treatments and educational programmes in the area of doctors' health

- Provide an environment for networking, exchange of information and leisure activity focused on staying healthy

The Call for Papers is now open and submissions can be accepted online at www.bma.org.uk/doctorshealthmatters The closing date for receipt of abstracts is Thursday 7 February 2008.

Put the date in your diary now and check www.bma.org.uk/doctorshealthmatters for further details.

For further information on the conference and the call for papers, please contact BMA Conferences on +44 (0)20 7383 6605/6137 or email doctorshealthmatters@bma.org.uk 